\title{
In memoriam R.J. Domenjoz
}

1908-1998

On March 7 this year, Prof. Robert J. Domenjoz died at the age of 89 years. Pharmacology is extremely indebted to him. He founded the journal in 1959, which was named Medicina Experimentalis and some years later renamed Medicina et Pharmacologia Experimentalis still in the tradition that Latin was the medical language. The final change took place when it became clear that the journal had focussed on drug actions; and therefore Pharmacology was the appropriate title.

Prof. Domenjoz served the journal as chief editor from the very beginning until 1977. His experience in many facettes of pharmacology made him the appropriate pioneer to start a new journal from scratch and to make it flourishing and accepted world-wide.

He was trained in pharmacology by prominent scientists, such as Profs. Heubner, Liljestrand, Schulemann and Straub. He gained further experience during his very fruitful activities as head of the pharmacological laboratories at Geigy in Basel. The development of several agents such as phenylbutazone and imipramine has been associated with his name. As a result of his successful activities in Basel, he was appointed Head of the Department of Pharmacology and Toxicology at the University of Homburg/Saar in 1949. From 1958 until he retired, he was Head of the Department of Pharmacology and Toxicology at the University of Bonn. During these periods he gradually focussed his interests on the pathophysiology and biochemistry of inflammation and the mechanism of action of antiinflammatory agents. Beyond his successful research activities, he was a dedicated academic teacher for many generations of students and young scientists.

He represented a personality with a highly cultivated life-style as collector of old and modern art and books, and even in his last years he loved to stroll around the countryside for hunting. Editors, the editorial board, readers and the publisher of Pharmacology will always remember what Prof. Domenjoz did for the journal. 